\title{
Effect of Physical and Chemical Treatments on the Electrical and Structural Properties of Water Hyacinth
}

\author{
Medhat Ibrahim ${ }^{*}, 1,2$, Ragab Mahani ${ }^{3}$, Osama Osman ${ }^{1}$ and Traugott Scheytt ${ }^{4}$ \\ ${ }^{1}$ Spectroscopy Department, National Research Center, NRC.,12311, Dokki, Cairo, Egypt \\ ${ }^{2}$ Physics Department, Faculty of Science, Jazan University, 2097 Jazan, Kingdom of Saudi Arabia \\ ${ }^{3}$ Microwave Physics and Dielectrics Department, National Research Center, NRC.,12311, Dokki, Cairo, Egypt \\ ${ }^{4}$ Technische Universität Berlin, Institut für Angewandte Geowissenschaften, Fachgebiet Hydrogeologie, D-13355, \\ Berlin
}

\begin{abstract}
Water hyacinths are aquatic plants that indicate a capability for pollutants uptake. Recently, further efforts have been made to increase the capacity of the plant to remediate the pollutants. Water hyacinth roots and shoots were analyzed using FTIR spectroscopy, XRF, and electrical investigations. Results of XRF analyses indicate that except for $\mathrm{Sr}, \mathrm{CaO}$, $\mathrm{Na}_{2} \mathrm{O}$, and $\mathrm{K}_{2} \mathrm{O}$, the level of metals as well as metal oxides are higher in plant root. FTIR measurements indicate that there are some similarities between the shoot and root molecular structures, with higher intensities in the shoot. Both plant parts were subjected to microwave heating up to 40 minutes at 450 and 900 Watt. A change in the crystallinity index resulted due to the microwave heating. Treating the plant with different concentrations of acetic acid and reaction time showed that the maximum degree of acetylation was at $0.05 \mathrm{~N}$ acetic acid for 19.0 hours. D-Gauss BLYP/DZVP indicates a change in the calculated dipole moment as a result of the treatment of the plant with acetic acid. The permittivity, dielectric loss, electric loss modulus, and AC conductivity of all samples were investigated in the frequency range between 42 and $10^{6}$ $\mathrm{Hz}$ at room temperature. These properties showed slight increase in case of control root samples compared to control shoot samples. However, two distinct relaxation processes were observed in the electrical loss modulus of these samples. The permittivity of root and shoot were considerably affected by microwave heating. It was also found that AC conductivity of water hyacinth plant showed relative increase by treating it with acetic acid at concentrations higher than $0.05 \mathrm{~N}$ for $19 \mathrm{~h}$. This can be considered as optimum conditions needed for water hyacinth plant to uptake more metal ions from wastewater.
\end{abstract}

Keywords: FTIR, phytoremediation, XRF, water hyacinth, permittivity.

\section{INTRODUCTION}

The phenomena of pollutants uptake by aquatic plant has been investigated at length $[1,2]$. Later water hyacinth received considerable attention because of its potential to remove pollutants, when used as a biological filtration system [3]. Water hyacinth showed a great ability to remove heavy metals, as well as other pollutants from polluted water [4]. In addition, it could also remove cadmium [5-7]; copper [8]; mercury [9]; ethion [10]; domestic sewage [11] and cyanide [12]. Accordingly, the utilization of water hyacinth as a phytoremediation tool has increased [13-15]. In our previous work, atomic emission spectroscopy was used to study the level of $\mathrm{Cu}, \mathrm{Pb}$, and $\mathrm{Ni}$ in water hyacinth root [16]. The electrical properties were estimated for plant root which was collected from the Nile [17]. Acetylated dry form of water hyacinth was used to mediate $\mathrm{Cd}$ [18]. This plant is further utilized alive to mediate $\mathrm{Cd}$ and $\mathrm{Pb}$, the ability of removal was less than compared to removal of $\mathrm{Cd}$ in case of acetylated dry plant [19]. Based upon modeling FTIR work, we treat the water hyacinth plant as cellulose like material

*Address correspondence to this author at the Spectroscopy Department, National Research Center, NRC., 12311, Dokki, Cairo, Egypt;

Tel: 002012 2727636; E-mail: medahmed6@yahoo.com
[20]. Because water hyacinth plant consists mainly of cellulose in addition to metal oxides and heavy metal ions and it can be therefore considered as composite. Its electrical performance is directly related to the permittivities and conductivities of its constituents [21]. The numerous strong polar groups of the cellulose molecules appointed to produce hydrogen bonds allowing the building up of complex structures within the molecule and between the different molecules. Although water hyacinth is utilized long time ago as effective phytoremediation tool it is still studied extensively as a hot research topic [22-26]

Accordingly, an investigation on the mechanism of uptake is needed to understand and control the uptake behavior of the plant. For that reason, the behaviors of metal ions together with the molecular structure of the plant were studied in this rationale. X-Ray Fluorescence (XRF) was used to evaluate the level of metals and metal oxides in the different plant parts. FTIR was used to study the molecular structures in the control, microwave heated and acetic acid treated water hyacinth. Furthermore, we have used dielectric spectroscopy measurements, in order to obtain some information about the dynamic molecular behavior of the water hyacinth plant, its dielectric properties and $\mathrm{AC}$ conductivity. Effects of electrical properties of the water 
hyacinth plant treated with acetic acid and microwave heating power were also investigated.

\section{EXPERIMENTAL METHODS}

Water hyacinth was collected from the River Nile at Cairo (Rod El-Farag), the plant was $150 \mathrm{~mm}$ length, it was kept to grow up in a special lagoon in the National Research Centre for three months in water free of pollutants. The plant was washed with tap water followed by double distilled water, then divided into two parts namely: root and shoot. These parts were dried at $105^{\circ} \mathrm{C}$ for $24 \mathrm{~h}$ and then ground to form a fine grained powder. For the dielectric measurements, the dried grained powder samples were pressed (under 6 ton) into discs with $2 \mathrm{~mm}$ in thickness and $10 \mathrm{~mm}$ in diameter.

The plant root and shoot were subjected to microwave heating for 10, 20, 30, and 40 minutes at 450 and 900 Watt.

Triplicate plants were immersed individually in acetic acid $0.025,0.05,010,0.25,0.33$, and $0.5 \mathrm{~N}$ for a constant time then triplicate plants were immersed in $0.05 \mathrm{~N}$ acetic acid for variant times from 0.5 up to 132 hours.

For FTIR measurement: Both plant parts were weighed (as $1 \% \mathrm{w} / \mathrm{w}$ ) with $\mathrm{KBr}$ and pressed in a $10 \mathrm{~mm}$ (diameter) disc.

For XRF: $6.0 \mathrm{~g}(<63 \mu \mathrm{m})$ dry plant (root and shoot individually) was mixed thoroughly with $1.5 \mathrm{~g}$ Hochst CWax then pressed in $40 \mathrm{~mm}$ Al-Cup.

\section{Calculation Details}

Molecular modeling calculations were carried out for cellulose using D-Gauss program package MOPAC 2002, as implemented in the CAChe Program by Fujitsu [27]. The geometries were optimized using DZVP basis set, together with the DFT method BLYP [28].

\section{Instrumentations}

Fourier Transform Infrared Spectrometer JASCO FTIR $300 \mathrm{E}$., in the range of $400-4000 \mathrm{~cm}^{-1}$, was applied to elucidate the molecular structure of the studied samples.

X-Ray Fluorescence (XRF) experiments were carried out using PHILIPS WD-RFA PW 2400 (program "Pulver"), at Technical University of Berlin, Institute of Applied Geosciences, Germany.

The dielectric properties such as capacitance $(C)$ and dissipation factor $(\tan \delta)$ of the prepared samples were measured using a computerized LRC meter (Hioki model $3531 \mathrm{Z} \mathrm{Hi}$ Tester). The dielectric properties of the investigated samples were carried out at room temperature in the frequency range between 42 and $10^{6} \mathrm{~Hz}$.

\section{RESULTS AND DISCUSSION}

\section{Levels of Heavy Metals and Metal Oxides in Water Hyacinth Root and Shoot}

In the present study, we have utilized X-Ray Fluorescence Spectroscopy (XRF) to determine the concentrations of both metals and metal oxides. As seen in Table 1, the concentration of $\mathrm{Sr}$ in the shoot is slightly higher than that in the root. As, $\mathrm{Ba}, \mathrm{Ce}, \mathrm{Co}, \mathrm{Cr}, \mathrm{Cu}, \mathrm{Mn}, \mathrm{Ni}, \mathrm{Pb}, \mathrm{V}$, $\mathrm{Zn}$, and $\mathrm{Zr}$ showed higher concentrations in the root as compared to the shoot. For the concentrations of metal oxides, we observed that the oxides of easily ionizable metals such as $\mathrm{CaO}, \mathrm{Na}_{2} \mathrm{O}$, and $\mathrm{K}_{2} \mathrm{O}$ were higher in the shoot than in the root, while the remaining metal oxides $\left(\mathrm{Al}_{2} \mathrm{O}_{3}\right.$, $\mathrm{Fe}_{2} \mathrm{O}_{3}, \mathrm{MgO}, \mathrm{TiO}_{2}, \mathrm{P}_{2} \mathrm{O}_{5}$, and $\mathrm{SO}_{3}$ ) were higher in the root than in the shoot. From this point of view the root possesses higher metal as well as metal oxides contents. Oxides of the easily ionizable metal (alkali metal) did not exhibit the same behavior.

Table 1. Concentration of Metals (ppm) as Well as Metal Oxides (\%) that Analyzed with XRF Technique

\begin{tabular}{|c|c|c|}
\hline Element & Shoot & Root \\
\hline As & $<4$ & 17 \\
\hline $\mathrm{Ba}$ & 84 & 194 \\
\hline $\mathrm{Ce}$ & $<20$ & 24 \\
\hline Co & 7 & 14 \\
\hline $\mathrm{Cr}$ & $<10$ & 37 \\
\hline $\mathrm{Cu}$ & 20 & 36 \\
\hline $\mathrm{F}$ & $<500$ & $<500$ \\
\hline $\mathrm{Mn}$ & 333 & 1632 \\
\hline $\mathrm{Ni}$ & $<3$ & 10 \\
\hline $\mathrm{Pb}$ & 21 & 247 \\
\hline $\mathrm{Sr}$ & 118 & 112 \\
\hline V & $<10$ & 42 \\
\hline $\mathrm{Zn}$ & 75 & 380 \\
\hline $\mathrm{Zr}$ & $<10$ & 33 \\
\hline $\mathrm{SiO}_{2}$ & $<16$ & $<16$ \\
\hline $\mathrm{Al}_{2} \mathrm{O}_{3}$ & $<0,50$ & 2.72 \\
\hline $\mathrm{Fe}_{2} \mathrm{O}_{3}$ & $<0,30$ & 0.86 \\
\hline $\mathrm{MgO}$ & 1.18 & 1.43 \\
\hline $\mathrm{CaO}$ & 2.24 & 1.89 \\
\hline $\mathrm{Na}_{2} \mathrm{O}$ & 0.62 & 0.35 \\
\hline $\mathrm{K}_{2} \mathrm{O}$ & 2.28 & 1.31 \\
\hline $\mathrm{TiO}_{2}$ & 0.01 & 0.13 \\
\hline $\mathrm{P}_{2} \mathrm{O}_{5}$ & 0.16 & 0.24 \\
\hline $\mathrm{SO}_{3}$ & 0.46 & 0.65 \\
\hline
\end{tabular}

\section{FTIR of the Water Hyacinth Root and Shoot}

Fig. (1) and Table 2 present the FTIR absorption bands of the water hyacinth root and shoot. The assignment of water hyacinth was discussed in our previous work $[18,29]$. The FTIR spectra of the water hyacinth could be assigned as follows.

The $\mathrm{OH}$ band of water appears at $3388.3 \mathrm{~cm}^{-1}$ while the $\mathrm{CH}$ of $\mathrm{CH}_{2}$ and $\mathrm{CH}_{3}$ form two bands at 2922.6 and 2852.2 $\mathrm{cm}^{-1}$, respectively. The stretching band of $\mathrm{C}=\mathrm{O}$ at $1738.4 \mathrm{~cm}^{-}$ ${ }^{1}$ is for the carboxyl group, this band is more clear in case of the shoot. Both the symmetric and asymmetric bands of $\mathrm{COO}$ at $1640.4 \mathrm{~cm}^{-1}$ and $1590.0 \mathrm{~cm}^{-1}$, are present in the IR 
spectrum and result from the metal carboxylate interactions. However, the first band is more clearly in case of the plant shoot. The C-O band of $\mathrm{CHO}$ is located at $1516.7 \mathrm{~cm}^{-1}$. The $\mathrm{OH}$ band can overlap with the N-H band which appears at $1422.2 \mathrm{~cm}^{-1}$. The $\mathrm{CH}$ of $\mathrm{CH}_{2}$ band is seen again at 1371.1 $\mathrm{cm}^{-1}$. The C-O band of the cellulose backbone appears at $1035.6 \mathrm{~cm}^{-1}$. The last part of the spectrum could be attributed to the vibrations of metal oxides.

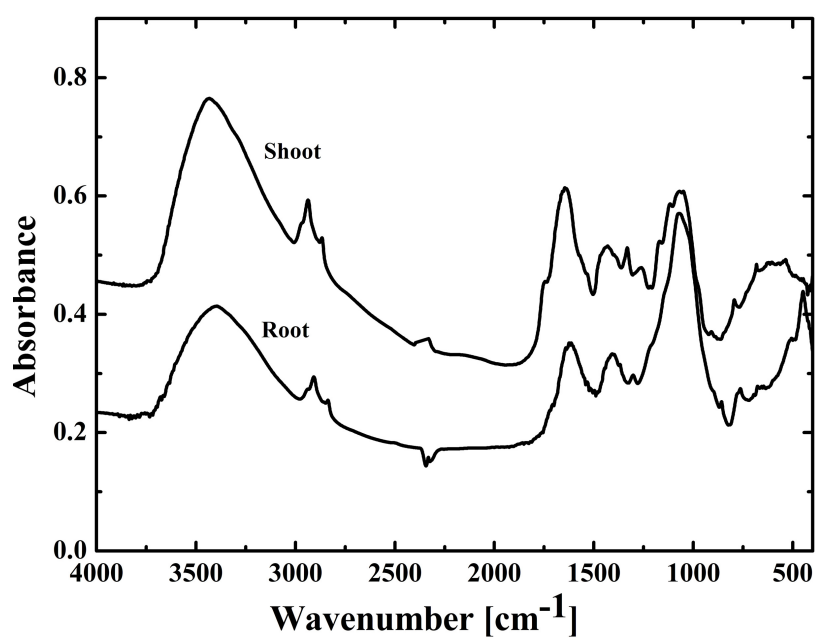

Fig. (1). FTIR absorption spectra of water hyacinth roots and shoot.

Table 2. FTIR Band Assignments and Wavenumbers as $\mathbf{c m}^{-1}$ for the Studied Water Hyacinth Shoot and Root

\begin{tabular}{|c|c|c|}
\hline \multicolumn{2}{|c|}{ Band Frequencies } & \multirow{2}{*}{ Band Assignment } \\
\hline \hline 3399.9 & 3388.3 & OH \\
\hline 3366.1 & & OH \\
\hline 2924.5 & 2922.6 & $\mathrm{CH}$ of $\mathrm{CH}_{2}$ \\
\hline 2854.1 & 2852.2 & $\mathrm{CH}$ of $\mathrm{CH}_{3}$ \\
\hline 1732.7 & 1738.5 & $\mathrm{C}=\mathrm{O}$ of COOH \\
\hline 1645.9 & 1634.4 & $\mathrm{C}-\mathrm{O}$ symm., \\
\hline 1624.7 & & $\mathrm{C}-\mathrm{O}$ symm., \\
\hline 1590.0 & & $\mathrm{C}-\mathrm{O}$ asymm., \\
\hline & 1516.7 & $\mathrm{C}-\mathrm{O}$ of $\mathrm{CHO}$ \\
\hline 1421.3 & 1422.2 & $\mathrm{C}-\mathrm{O}$ of $\mathrm{COO}$ \\
\hline 1384.6 & 1384.6 & OH phenolic \\
\hline 1318.1 & 1371.1 & $\mathrm{CH}$ of CH${ }_{2}$ \\
\hline 1035.6 & 1035.6 & $\mathrm{C}-\mathrm{O}$ of cellulose backbone \\
\hline
\end{tabular}

A special interest will be focused to the $\mathrm{C}=\mathrm{O}$ region in order to trace the effect of acetic acid treatment.

\section{Effect of Microwave Heating}

The plant was subjected to microwave heating for different times up to $40 \mathrm{~min}$ using two powers namely, 450 and 900 Watt. As a general trend, no changes were recorded in the molecular structure of both the root and the shoot. In the region of $2000 \sim 1000 \mathrm{~cm}^{-1}$ a change in the crystallinity index A1371/A2922 [30, 31] took place. The calculated crystallinity index is seen in Figs. $(\mathbf{2}, \mathbf{3})$ and Table $\mathbf{3}$. Generally, a slight increase in crystallinity is noticed. This could be due to dehydration of water in root as well as shoot samples. Furthermore, shoot samples are slightly affected compared to root samples. This may be due to the dominant cellulosic structure in the shoot. Finally, a partial crystallinty is given to the plant as a result of microwave heating.

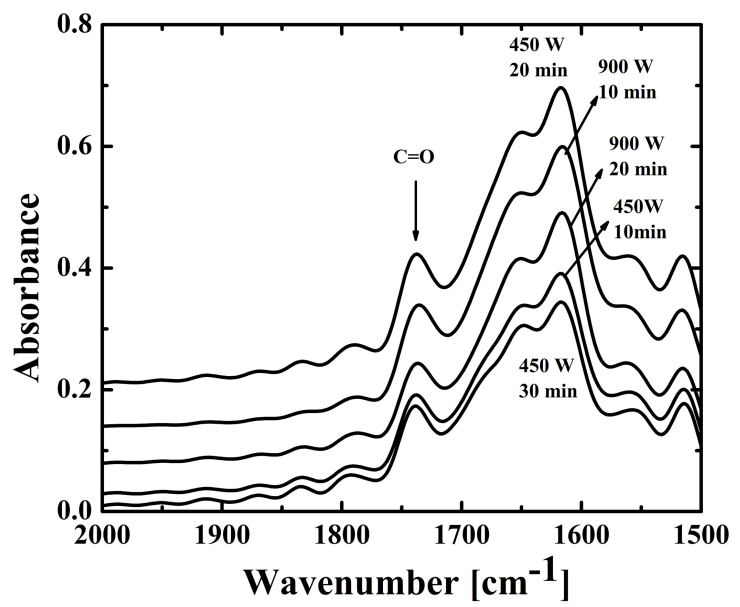

Fig. (2). FTIR absorption spectra (deconvolution) of water hyacinth shoot that treated with microwave heating at different times and powers.

Table 3. Calculated Crystallinity Index for the Plant Root as Well as Shoot After Treatment with Microwave Using 450 and 900 Watt at 10, 20 and 30 Minutes

\begin{tabular}{|c|c|c|c|}
\hline \multirow{2}{*}{ Time (min) } & \multirow{2}{*}{ Power (watt) } & \multicolumn{2}{|c|}{ Crystallinity Index } \\
\cline { 3 - 4 } & & Root & Shoot \\
\hline \hline 10 & 450 & 0.75 & 1.13 \\
\hline 10 & 900 & 0.93 & 1.10 \\
\hline 20 & 450 & 1.09 & 1.21 \\
\hline 20 & 900 & 1.05 & 1.24 \\
\hline 300 & 450 & 1.03 & 1.18 \\
\hline
\end{tabular}

\section{Effect of Acetic Acid Treatment}

Treating water hyacinth with acetic acid increases its ability for removing heavy metals from aquatic environment [19]. Accordingly water hyacinth was treated with acetic acid at different acid concentrations and for different times. It was proposed that as far as water hyacinth absorb solution containing acetic acid, the acid will exist in free form i.e. it will not react with the plant contents. In our previous work $[19,29]$, FTIR spectra of acid treated plant indicate the absence of unreacted acetic acid bands. Furthermore, Adebajo [32] studied the interaction between acetic acid and cellulose, he stated that the absence of unreacted acetic acid bands $\left(1800-1760 \mathrm{~cm}^{-1}\right)$ is an indication for acetylation process. The same concept could be applied for water hyacinth whereas we introduced that the plant is cellulose like material $[20,32]$. 


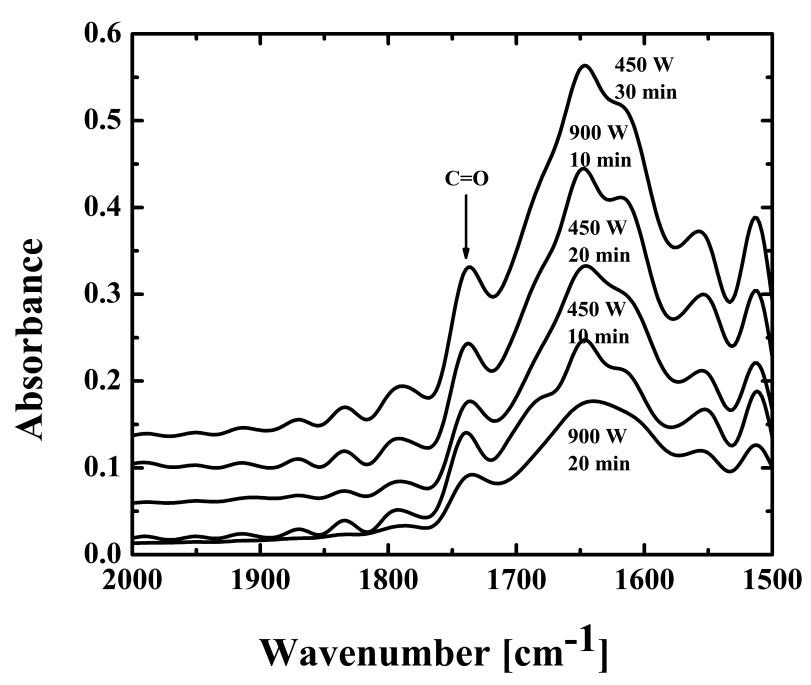

Fig. (3). FTIR absorption spectra (deconvolution) of water hyacinth root treated with microwave heating at different times and powers.

Based upon these considerations; treating the water hyacinth with acetic acid leads to the acetylation of the plant. The effect of acid concentrations and times of treatments are indicated in terms of the calculated degree of acetylation. As far as the plant was chemically treated with acetic acid an increase in the intensity of $\mathrm{C}=\mathrm{O}$ band can be noticed in the plant shoot as well as in the root. The degree of acetylation is calculated as $\mathrm{A}_{1736} / \mathrm{A}_{1035}$ [33] and listed in Tables 4 and 5 respectively.

Table 4. Calculated Degree of Acetylation $\left(\mathrm{A}_{1736} / \mathbf{A}_{1035}\right)$ for Water Hyacinth Root and Shoot for $0.05 \mathrm{~N}$ at Different Times

\begin{tabular}{|c|c|c|}
\hline Time (Hours) & Root & Shoot \\
\hline \hline 0.0 & 0.190 & 0.783 \\
\hline 0.5 & 0.433 & 0.603 \\
\hline 1.0 & 0.337 & 0.665 \\
\hline 2.0 & 0.240 & 0.693 \\
\hline 4.0 & 0.220 & 0.652 \\
\hline 12.0 & 0.329 & 0.601 \\
\hline 19.0 & 0.472 & 0.633 \\
\hline 39.0 & 0.276 & 0.644 \\
\hline 132.0 & 0.654 & 0.645 \\
\hline
\end{tabular}

The degree of acetylation $\left(\mathrm{A}_{1736} / \mathrm{A}_{1035}\right)$ was calculated according to [33].

A transport of acetate took place in earlier time (from 30 min up to 4.0 hours) from root to shoot. Both plant parts were subjected to acetic acid for different concentrations (up to $0.5 \mathrm{~N}$ ) and time durations (up to 132 hours). As a result of treating water hyacinth with different acetic acid concentration, one can observe that a higher degree of acetylation occurs with $0.05 \mathrm{~N}$ acetic acid for 19.0 hours.

In order to follow up the changes in the molecular structure of the plant as a result of acetylation molecular modeling was utilized. A model molecule of $\beta$-D glucose is used as a building unit of cellulose; the carbon atoms are numbered as seen in Fig. (4).

Table 5. Calculated Degree of Acetylation $\left(A_{1736} / A_{1035}\right)$ for Water Hyacinth Root and Shoot for 19 Hours at Different Acetic Acid Concentrations

\begin{tabular}{|c|c|c|}
\hline Concentration & Root & Shoot \\
\hline \hline 0.0 & 0.19048 & 0.78309 \\
\hline 0.025 & 0.30395 & 0.62267 \\
\hline 0.050 & 0.4717 & 0.63291 \\
\hline 0.100 & 0.11834 & 0.62461 \\
\hline 0.250 & 0.19084 & 0.61425 \\
\hline 0.330 & 0.25773 & 0.59737 \\
\hline 0.500 & 0.33223 & 0.59418 \\
\hline
\end{tabular}

The degree of acetylation $\left(\mathrm{A}_{1736} / \mathrm{A}_{1035}\right)$ was calculated according to [33].

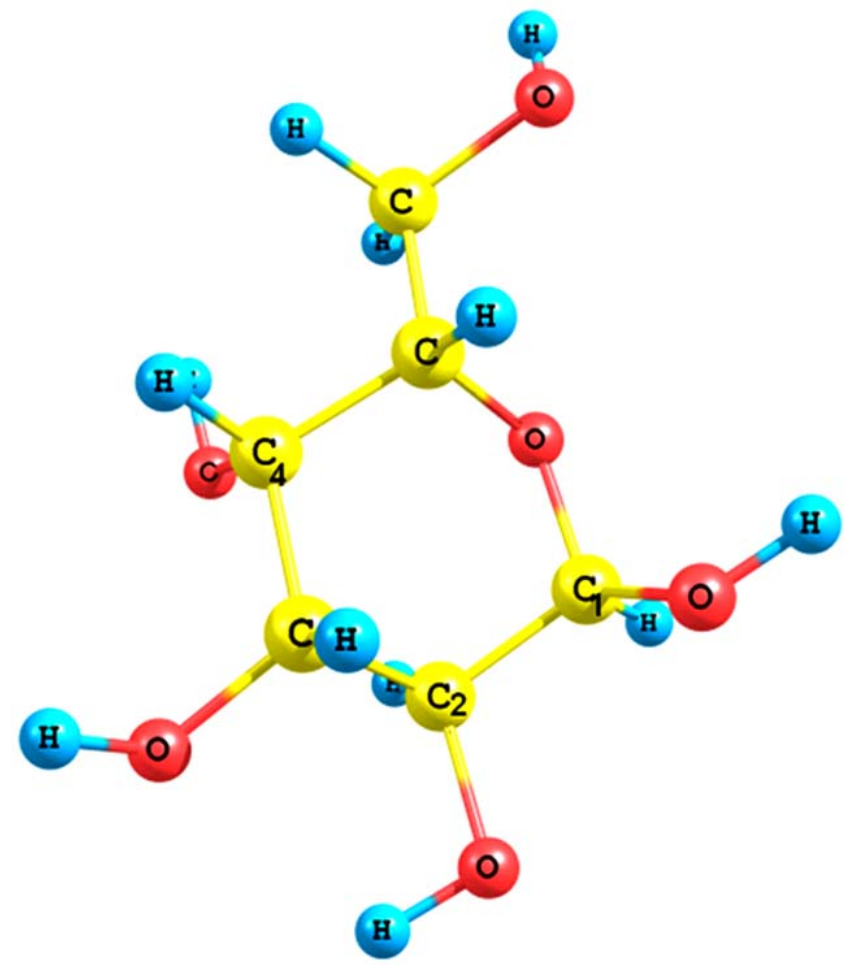

Fig. (4). Optimized D - Gauss BLYP/DZVP model structure for the studied model molecule indicating the carbon sites.

Using D - Gauss BLYP/DZVP model it is postulated that acetic acid interacts with the typical $\mathrm{OH}$ of cellulose $\left(\mathrm{CH}_{2} \mathrm{OH}\right)$ forming $\mathrm{H}_{2} \mathrm{O}$ which is the common definition of acetylation. We propose in our previous work another scheme which is not common and/or never treated before. $\mathrm{COOH}$ of acetic acid is moving freely and hence from the modeling point of view we replace $\mathrm{OH}$ with the free $\mathrm{COOH}$ then running our calculations. From this modeling point of view $\mathrm{COOH}$ forms stable mono- $\mathrm{COOH}$ structure only as $\mathrm{COOH}$ replaces the $\mathrm{OH}$ of $\mathrm{CH}_{2} \mathrm{OH}$; $\mathrm{OH}$ corresponding to carbon number (3). Also two $\mathrm{COOH}$ could replace two $\mathrm{OH}$ forming di-COOH; as it replaces the two $\mathrm{OH}$ attached to carbon numbers (1) and (2). Total dipole moment was 
calculated using D-Gauss BLYP/DZVP model for cellulose, cellulose mono- $\mathrm{COOH}$ and cellulose di-COOH. The results in Table 6 indicate that a change in the dipole moment of cellulose took place as $\mathrm{COOH}$ interacts with cellulose.

Table 6. Calculated Total Dipole Moment as Debye with its Distribution in $x, y$ and $z$ Directions, Energy Gap $(\Delta \mathbf{E}$ ev) for Cellulose, Cellulose Mono-Acetate and Cellulose Di-Acetate Using BLYP/DZVP Model

\begin{tabular}{|c|c|c|c|c|c|c|}
\hline & \multicolumn{5}{|c|}{ Dipole Moment } & \multirow{2}{*}{$\Delta \mathbf{E}$} \\
\cline { 2 - 5 } & $\mathbf{X}$ & $\mathbf{Y}$ & $\mathbf{Z}$ & Total & \\
\hline \hline Cellulose & -3.558 & -2.385 & 1.252 & 4.463 & 12.945 \\
\hline COOH Interaction with Cellulose \\
\hline Cellulose mono-acetate $\left(\mathrm{CH}_{2} \mathrm{OH}\right)$ & -2.300 & 2.476 & -2.915 & 4.463 & 11.755 \\
\hline Cellulose mono-acetate (3) & -3.492 & -2.860 & 0.334 & 4.526 & 11.814 \\
\hline Cellulose di-acetate (1-2) & 1.266 & 0.103 & -1.829 & 2.227 & 11.585 \\
\hline Acetic Acid Interaction with Cellulose \\
\hline Cellulose mono-acetate (CH $\left.\mathrm{CH}_{2} \mathrm{OH}\right)$ & -0.304 & 2.701 & -0.382 & 2.745 & 11.817 \\
\hline Cellulose mono-acetate (3) & -1.902 & -1.456 & -2.736 & 3.637 & 11.742 \\
\hline Cellulose di-acetate (1-2) & -2.190 & 2.577 & 0.917 & 3.504 & 11.770 \\
\hline
\end{tabular}

A slight decrease in total dipole moment took place as $\mathrm{COOH}$ forms mono- $\mathrm{COOH}$ structure while a sharp decrease in dipole moment took place when $\mathrm{COOH}$ finds its way as di- $\mathrm{COOH}$ onto the model molecule. As seen from the calculated band gap energy di-acetate is the most likely structure whenever $\mathrm{COOH}$ interacts with cellulose which agrees with our previous results [20].

From modeling work a stable structure is obtained as $\mathrm{COOH}$ replaces and/or interacts with $\mathrm{OH}$ of cellulose. Furthermore, the $\mathrm{OH}$ is not only that of $\mathrm{CH}_{2} \mathrm{OH}$ but also to other $\mathrm{OH}$. Table 6 presents another important physical parameter which is the HOMO/LUMO band gap energy. This calculated parameter indicates that as $\mathrm{COOH}$ interacts and/or replaces $\mathrm{OH}$ a decrease in band gap energy took place. This decrease in band gap energy allows the metals in the aquatic environment to interact with the treated plant.

Collecting the above data, one can conclude that acetic acid causes a change in the total dipole moment with its contributions in $\mathrm{x}, \mathrm{y}$ and $\mathrm{z}$ direction regardless whether $\mathrm{COOH}$ replaces or interacts with the $\mathrm{OH}$ of the model molecule. Also the band gap energy is decreased as a result of interaction of acetic acid with the model molecule.

Correlating model molecule results with those of experimental findings one can notice the following. Treating the plant chemically with acetic acid enhances the total dipole moment which in turn increases its ability for interaction in the aquatic environment. As the plant is physically heated with microwave the crystalinity is partially enhanced. By comparison between chemical and physical treatments, the partial enchantment in the crystalinity of water hyacinth could in turn enhance its ability for removing pollutants from aquatic environment. In order to understand the role of both physical and chemical treatment the dielectric properties of treated plant will be studied and compared with the untreated plant.

\section{Dielectric Properties of Water Hyacinth}

The electrical properties of a material held between two plane parallel electrodes of area $A$ separated by a distance $d$ are completely characterized by the measured electrical capacitance and conductance.

Fig. (5a, b) represents the frequency dependence of the permittivity $\left(\varepsilon^{\prime}\right)$, dielectric loss $\left(\varepsilon^{\prime \prime}\right)$, for the investigated control root and shoot plant samples. From this figure $\varepsilon^{\prime}$ and $\varepsilon^{\prime \prime}$ for both parts of the plant showed rapidly decrease with increasing frequency that followed by slower decrease at frequencies higher than $5 \times 10^{3} \mathrm{~Hz}$, see the vertical dashed line. At sufficiently low frequency, there is a rapid increase of both $\varepsilon^{\prime}, \varepsilon^{\prime \prime}$ with frequency decrease. The high values of $\varepsilon^{\prime}$, $\varepsilon^{\prime \prime}$ at low frequencies make it easy to identify the effects of blocking electrodes. More specifically, in Fig. (5a) the apparent permittivity is large, indicating the existence of the so called electrode polarization $[34,35]$. In Fig. (5b) the dielectric loss also becomes large at low frequencies, due to the 'free charge' motion within the material. These values do not correspond, of course, to the bulk dielectric function but rather due to 'free charge' build up at the interface between the material and the electrodes. For very low frequencies, there is practically time for the charges to build up at this interface before the field changes direction, giving a very large effective value of $\varepsilon^{\prime}$. With increasing frequency there is no time for the build up of the charge at the interface but only for the build up at the boundaries of the conducting species in the material and at the ends of the conducting paths. This phenomenon leads to the so called conductivity relaxation. At frequencies lower than $5 \times 10^{3} \mathrm{~Hz}, \varepsilon^{\prime}$ of root was observed at relatively higher values compared to those of the shoot. This may be due to the higher concentration of metal ions (As, $\mathrm{Ba}, \mathrm{Ce}, \mathrm{Co}, \mathrm{Cr}, \mathrm{Cu}, \mathrm{Mn}, \mathrm{Ni}, \mathrm{Pb}, \mathrm{V}, \mathrm{Zn}$, and $\mathrm{Zr}$ ) in root compared to those for the shoot.

In order to observe the possible relaxation processes taking place in the control samples, their electric loss modulus $\left(M^{\prime \prime}\right)$ [36] were plotted also as a function of frequency (Fig. 5c). From this figure, although no significant changes can be seen in the dielectric loss curves, two distinct relaxation peaks were observed in the corresponding $M^{\prime \prime}$ curves. One relaxation peak characterized by higher intensity at $v_{m} \sim 1.5 \times 10^{3} \mathrm{~Hz}$ represents the control root plant sample, whereas the second relaxation peak with lower intensity indicated at $v_{m} \sim 5 \times 10^{3} \mathrm{~Hz}$ represents the control shoot plant sample. These processes presumably involve a dipolar activity and could be associated with the co-operative motion of the dipolar functional group, probably the $\mathrm{CH}_{2} \mathrm{OH}$ groups and could be affected by the number of these groups. In addition, the corresponding relaxation times $\left(\tau=1 / 2 \pi v_{m}\right)$ describing these peaks for both root and shoot plant samples were given, respectively at $1 \times 10^{-4} \mathrm{~s}$ and $3.2 \times 10^{-5} \mathrm{~s}$, where $\tau$ is defined as the time needed for dipoles to relax to their equilibrium positions after removing the electric field. The reciprocal of relaxation time is related to the mobility of dipoles or charge carriers [37]: the longer $\tau$, the slower the dipole motion. Then, the obtained differences in relaxation time of control samples may originate from the differences in concentration of the dipolar groups in the cellulose chain in addition to the differences in interchain interactions. The interactions between chains include hydrogen bonding, dipole - dipole, ion-dipole and dispersion forces. The 
interchain forces constrain the dipolar group motion and then affect the magnitude of the peak height [38]. This suggests that the orientational freedom of the side groups is restricted owing to the hydrogen bonding between neighboring parallel chains. The cellulose structure is more complicated in root than in shoot plant samples, a broader absorption peak was observed in root plant sample compared to the shoot
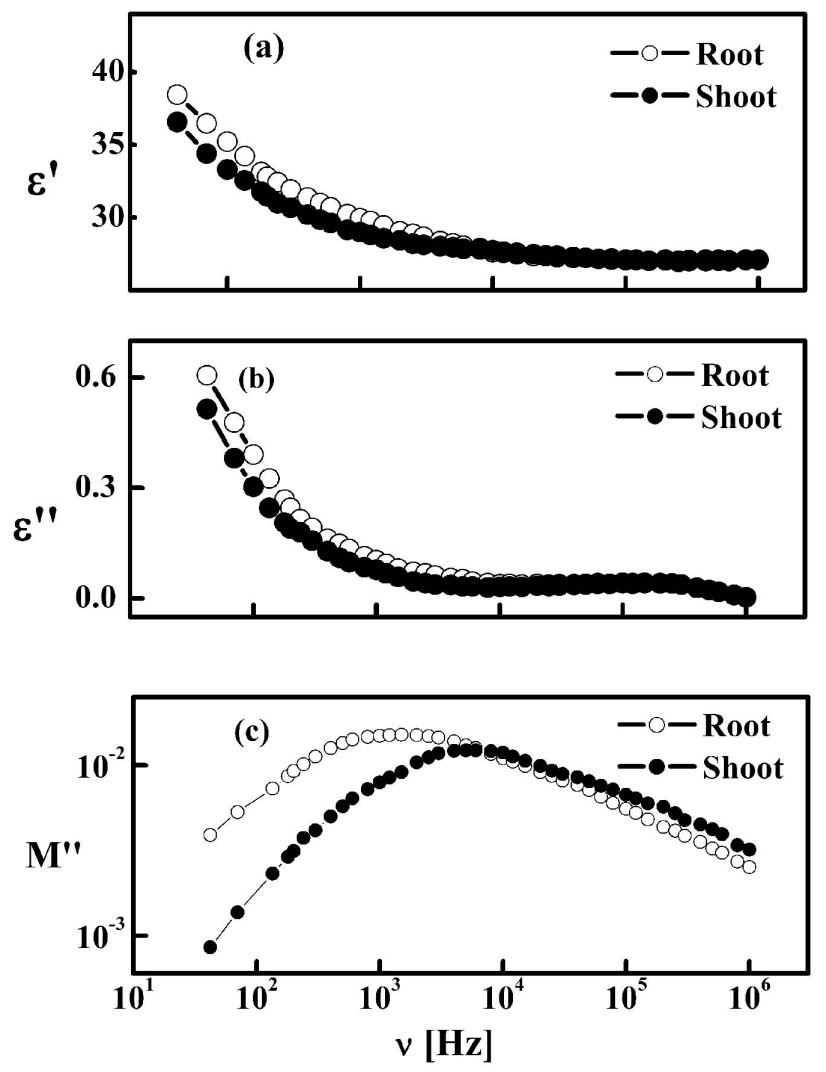

Fig. (5). The frequency dependence of the permittivity (a), dielectric loss (b) and the electrical loss modulus (c) for root and shoot of water hyacinth plant, measured at room temperature.

\section{Effect of Microwave Heating on Permitivity}

Fig. (6) presents the frequency dependence of permittivity $\left(\varepsilon^{\prime}\right)$ of the control root and shoot plant samples comparing with that treated by microwave heating power (450 and 900 Watts), for 10, 20,30, and 40 minutes. There is evidence from this figure that $\varepsilon^{\prime}$ showed remarkable decrease for all treated compared to the control samples. The observed decrease in samples permittivity could be due to crystallization taking place during heating by microwave. After crystallization, the sample becomes a composite medium comprising amorphous and crystalline phases. The development of crystalline structures during heating results in a decrease of sample polarization and therefore a decrease in the dielectric properties should be expected. It is also noticed that the highest values of crystallinity recorded for the root and shoot plant samples (see Table 3) are corresponding with their lowest values seen in $\varepsilon^{\prime}$, see Fig. (6a1, b2).

For more detailed discussion, $\varepsilon^{\prime}$ of the root and the shoot samples treated with different microwave heating powers for 20 minutes was plotted as a function of frequency Fig. (7).
This figure shows that $\varepsilon^{\prime}$ of shoot samples are slightly more affected by crystallinity than those of root samples. Accordingly, $\varepsilon^{\prime}$ of shoot plant samples exhibit higher values than those obtained for the root ones. This may be due to the dehydration of water (increase of crystallinity) in root as well as shoots samples or due to the dominant cellulosic structure in shoot samples. In addition, $\varepsilon^{\prime}$ of root samples increase with the increase of microwave heating power whereas it showed an inverse behavior for the shoot samples. As a result of hydroxyl groups showing different polarities, cellulose has different crystalline structures, ranging from cellulose I (native cellulose) to cellulose IV [39]. The differences in the dielectric behavior of root and shoot may be interpreted regarding this point of view.

\section{Effect of Acetic Acid on the Dielectric Loss and} Conductivity

The effect of acetic acid $\left(\mathrm{CH}_{3} \mathrm{COOH}\right)$ with different concentrations on the dielectric loss and conductivity of the root and the shoot plant samples are shown in Fig. (8). Compared to the control root and shoot plant samples (free of acetic acid), slight changes can be noticed in $\varepsilon^{\prime \prime}$ and $\sigma_{a c}$. For the root plant samples, $\varepsilon^{\prime \prime}$ and $\sigma_{a c}$ showed slight decrease with the increase in acetic acid concentrations up to $0.05 \mathrm{~N}$ and then followed by a slight increase at higher concentrations. $\sigma_{a c}$ exhibits similar behavior for the shoot plant samples. This result can be attributed to the higher degree of acetylation that took place at $0.05 \mathrm{~N}$ acetic acid for 19.0 hours Table 6 . It was noted that the interaction of acetic acid with the cellulose mono - acetate (3) resulted in an increase of the total dipole moments, which indicate an increase of polarization. Thus, the observed increase in $\varepsilon^{\prime \prime}$ with increasing $\mathrm{CH}_{3} \mathrm{COOH}$ concentrations may be explained according to this assumption. While interaction of free $\mathrm{COOH}$ with cellulose mono - acetate of the primary position $\left(\mathrm{CH}_{2} \mathrm{OH}\right)$ or cellulose di - acetate (1-2) and interaction of acetic acid with cellulose, all result in a decrease of total dipole moments and therefore the observed decrease in $\varepsilon^{\prime \prime}$ could also be explained according to the second assumption. On the other hand, conductivity of the root and the shoot plant samples showed continuous increase with increasing $\mathrm{CH}_{3} \mathrm{COOH}$ concentrations higher than $0.05 \mathrm{~N}$. Above this concentration, $\mathrm{CH}_{3} \mathrm{COOH}$ may increase mobility of charge carriers passing through water hyacinth plant. From this point of view, treating water hyacinth with acetic acid increases its ability for uptake metal ions from the aquatic environment.

\section{CONCLUSION}

Analyzing both the root and the shoot with XRF revealed that, except $\mathrm{Sr}, \mathrm{CaO}, \mathrm{Na}_{2} \mathrm{O}$, and $\mathrm{K}_{2} \mathrm{O}$, the level of metals as well as metal oxides in the shoot is lower than that in the root. FTIR results indicated that there were no changes in the molecular structure as a result of microwave heating up to 900 Watt. Microwave heating produces partial enhancement in the crystallinity of the studied samples. Also no structural change was recorded for a heating time up to $40 \mathrm{~min}$. Thus; the changes are proposed to be regarded in terms of the electrical properties.

The obtained electrical properties for the control root and shoot plant samples showed very slight changes in their 
Root
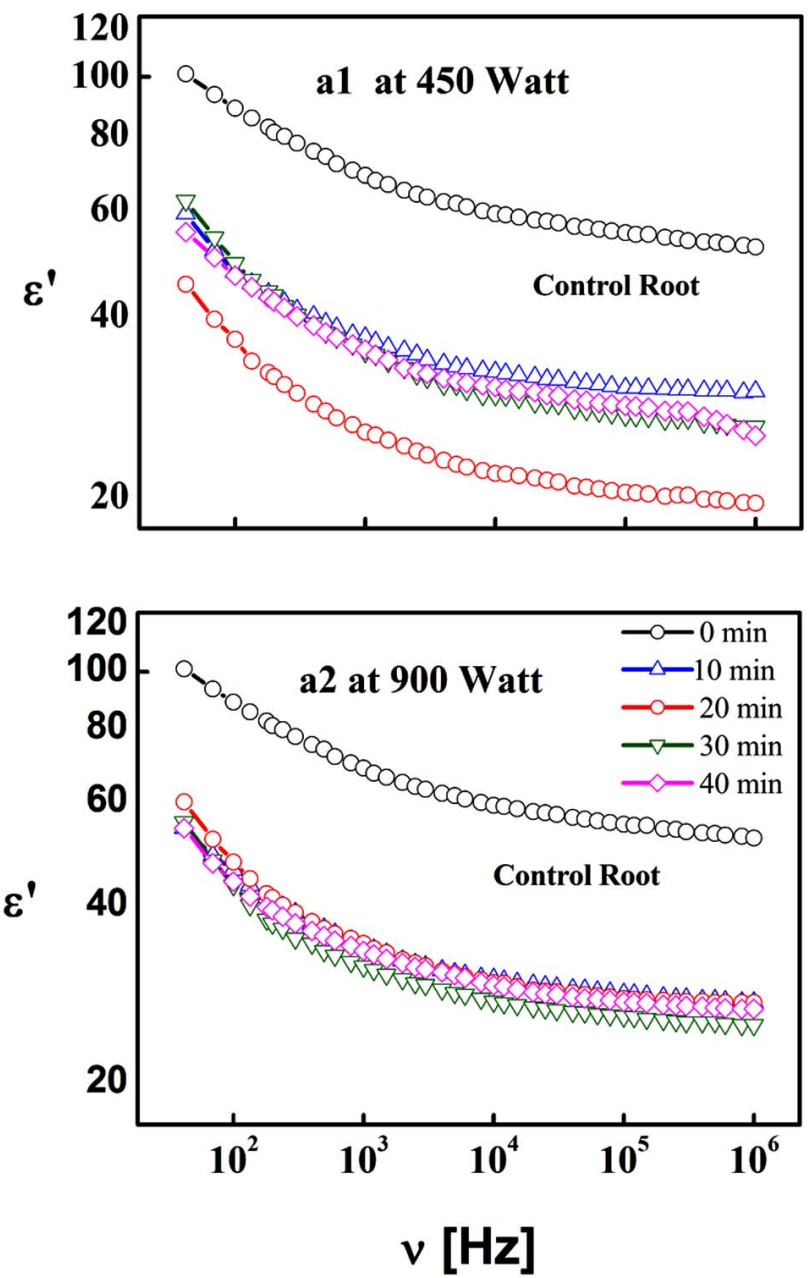

Shoot

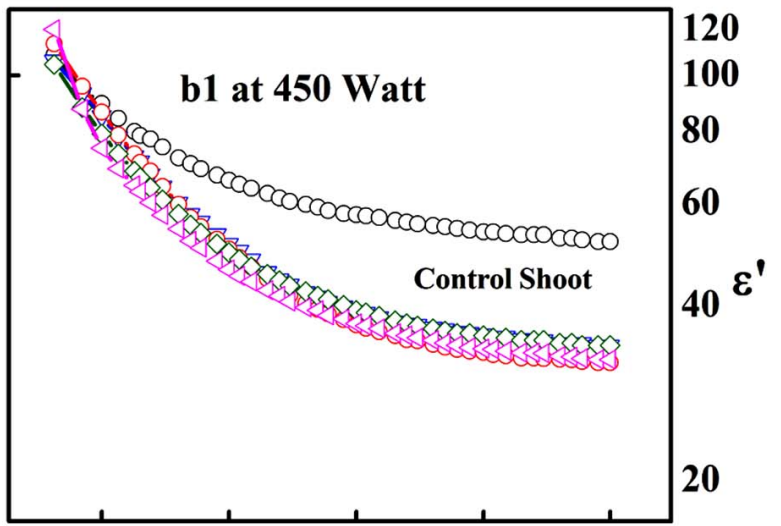

120

100

80

60

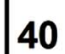

$\boldsymbol{E}^{\prime}$

Fig. (6). The frequency dependence of the permittivity of root and shoot plant samples treated with microwave heating power for different times compared to the untreated control root and shoot samples.

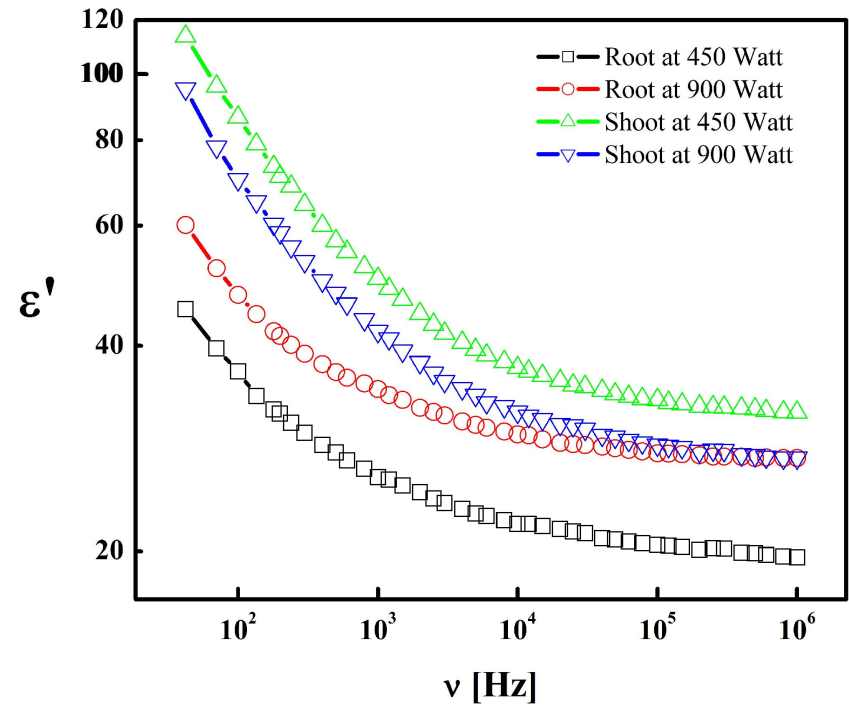

Fig. (7). The frequency dependence of the permittivity of root and shoot plant samples treated with microwave heating power for 20 minutes. permittivity $\left(\varepsilon^{\prime}\right)$, dielectric loss $\left(\varepsilon^{\prime}\right)$. However, their electric loss modulus $\left(M^{\prime \prime}\right)$ showed two pronounced relaxation processes of characteristic movements of $\mathrm{CH}_{2} \mathrm{OH}$ groups in both the root and the shoot plant samples. As compared to the control samples, the permittivity of the samples treated by microwave heating power exhibit remarkable change due to the dehydration of water which in turn affects the crystallinity. The dielectric loss and AC conductivity of the samples were significantly affected from treatment with acetic acid with different concentrations for $19 \mathrm{~h}$. In particular, at concentration lower than $0.05 \mathrm{~N}$, the electrical properties of the samples showed a slight decrease whereas they showed a slight increase at higher concentrations when compared to the control. Interestingly, the observed increase in the $\varepsilon^{\prime \prime}$ seemed to be in agreement with the assumption that an interaction of acetic acid with cellulose mono - acetate (3) increases the total dipole moments. Then the observed decrease in the $\varepsilon^{\prime \prime}$ seemed to be in agreement with the assumption of an interaction of $\mathrm{COOH}$ with cellulose mono acetate $\left(\mathrm{CH}_{2} \mathrm{OH}\right)$ or cellulose $\mathrm{di}$ - acetate (1-2) and interaction of acetic acid with cellulose. Finally, the increase in total dipole moment as indicated with modeling and the enhancement in electrical properties and crystallinity 

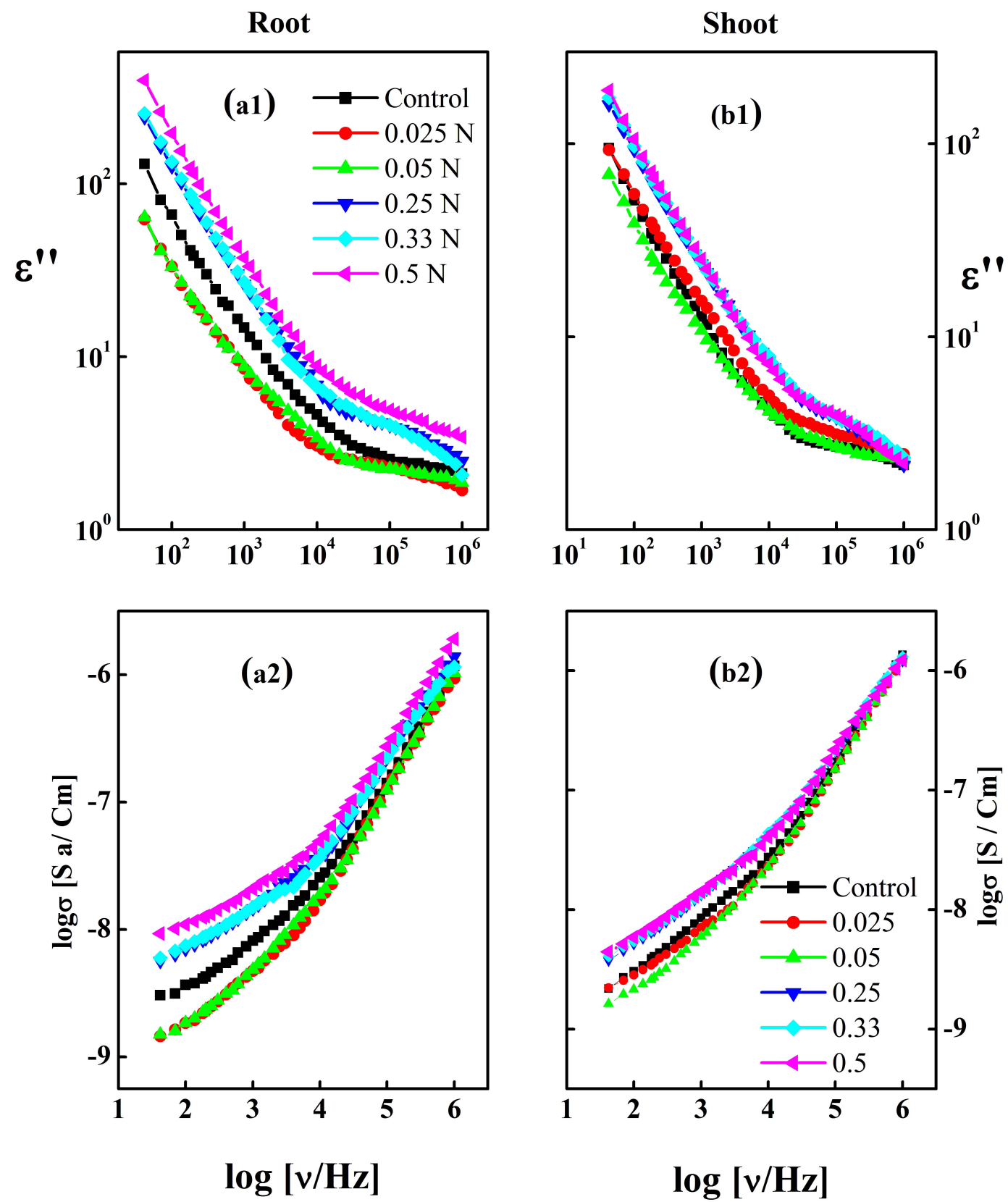

Fig. (8). The frequency dependence of $\varepsilon^{\prime \prime}(\mathrm{a} 1, \mathrm{~b} 1)$ and $\sigma(\mathrm{a} 2, \mathrm{~b} 2)$ for the water hyacinth plant root and shoot that were subjected to $\mathrm{CH}_{3} \mathrm{COOH}$ with different concentrations for $19 \mathrm{~h}$.

dedicate water hyacinth which is treated by acetic acid for better uptake of heavy metals from the aquatic environment. The present efforts together with those results obtained in our previous work are attempts to understand the mechanism of pollution control by the plant water hyacinth [32].

\section{ACKNOWLEDGEMENTS}

The authors would like to express their thanks to Prof. Dr. Ahmed Fakhry Prof. of Spectroscopy, Spectroscopy Department, National Research Center, Egypt and Prof. Dr. Ahmed Ghoneim, Prof. of Microwave Physics and Dielectrics, Microwave and Dielectric Department, National Research Center, Egypt, for their kind revision of the paper.

\section{REFERENCES}

[1] Wells JR, Kaufman PB, Jones JD. Heavy metal contents in some macrophytes from Saginaw Bay (Lake Huron, USA). Aquat Bot 1980; 9: 185-93.

[2] Wolverton C, Macdonald RC. Water hyacinths and alligator weeds for final filtration of sewage. Technical Memorandum TM-X72729. Washington, D.C.: NASA 1975.

[3] Muramoto S, Oki Y. Removal of some heavy-metals from polluted water by water hyacinth (Eichhornia-Crassipes). Bull Environ Contam Toxicol 1983; 30: 170-7.

[4] Rosas I, Carbajal ME, Gómez-Arroyo S, Belmont R, VillalobosPietrini R. Cytogenetic effects of cadmium accumulation on water hyacinth (Eichchornia Crassipes). Environ Res 1984; 33: 386-95.

[5] Das S, Jana BB. Distribution pattern of ambient cadmium in wetland ponds distributed along an industrial complex. Chemosphere 2004; 55: 175-85. 
[6] Hasan SH, Talat M, Rai S. Sorption of cadmium and zinc from aqueous solutions by water hyacinth (Eichchornia Crassipes). Biores Techn 2007; 98: 918-28.

[7] So LM, Chu LM, Wong PK. Microbial enhancement of $\mathrm{Cu}^{2+}$ removal capacity of Eichchornia Crassipes (Mart.). Chemosphere 2003; 52: 1499-503.

[8] Skinner K, Wright N, Porter-Goff E. Mercury uptake and accumulation by four species of aquatic plants. Environ Pollut 2007; 145: 234-7.

[9] Huilong X, Xiangjuan M. Phytoremediation of ethion by water hyacinth (Eichchornia Crassipes) from water. Biores Techn 2006; 97: 1050-4.

[10] Youngchul K, Giokas DL, Jin-Woo L, Paraskevas PA. Potential of natural treatment systems for the reclamation of domestic sewage in irrigated agriculture. Desalination 2006; 189: 229-42.

[11] Mathias E, Evangelou MWH, Schaeffer A. Cyanide phytoremediation by water hyacinths (Eichchornia Crassipes). Chemosphere 2007; 66: 816-23.

[12] Ntengwe FW. An overview of industrial wastewater treatment and analysis as means of preventing pollution of surface and underground water bodies - the case of Nkana mine in Zambia. Phys Chem Earth Parts A-C 2005; 30: 726-34.

[13] Maine MA, Suñe N, Hadad H, Sánchez G, Bonetto C. Nutrient and metal removal in a constructed wetland for wastewater treatment from a metallurgic industry. Ecologic Eng 2006; 26: 341-7.

[14] Mishima D, Tateda M, Ike M, Fujita M. Comparative study on chemical pretreatments to accelerate enzymatic hydrolysis of aquatic macrophyte biomass used in water purification processes. Biores Techn 2006; 97: 2166-72.

[15] Verma VK, Singh YP, Rai JPN. Biogas production from plant biomass used for phytoremediation of industrial wastes. Biores Techn 2007; 98: 1664-9.

[16] Ibrahim M. Development of a spectroscopic technique for the study of water hyacinth as indicator for pollutants. Thesis, Physics Department, Faculty of Science, Cairo University 1996

[17] Ahmed MA, El Bahy GS, Ibrahim M. Spectroscopic and electrical study of water hyacinth root. Bull NRC Egypt 2004; 29: 523-33.

[18] Ibrahim M, Scheytt T. Increasing the ability of Water hyacinth for removing Cadmium, Second International Congress on Environmental Planning and Management, TU Berlin, Berlin, Germany 2007; pp. 231-54

[19] Ibrahim M, Shaltout AA, Soylak M, Jalbout, Kamal D-E. Removal of $\mathrm{COOH}, \mathrm{Cd}$ and $\mathrm{Pb}$ using water hyacinth: FTIR and Flame atomic absorption study. J Iran Chem Soc 2009; 6: 364-72.

[20] Ibrahim M, Osman O. Spectroscopic analyses of cellulose: Fourier Transform infrared and molecular modelling study. J Comput Theor Nanosci 2009; 6: 1054-8

[21] Wang F, Leung AOW, Wu SC, Yang MS, Wong MH. Chemical and ecotoxicological analyses of sediments and elutriates of contaminated rivers due to e-waste recycling activities using a diverse battery of bioassays. Environ Pollut 2009; 157: 2082-90.

[22] Tejeda S, Zarazúa G, Ávila-Pérez P, Carapia-Morales L, Martínez L. Total reflection X-ray fluorescence spectrometric determination of elements in water hyacinth from the Lerma River, Spectrochimica Acta Part B: Atomic Spectroscopy 2010; 65: 4838.

[23] Pushpa GS, John CV. Does water hyacinth (Eichchornia Crassipes) compensate for simulated defoliation? Implications for effective biocontrol. Biol Control 2010: 54: 35-40.

[24] Cathryn O'S, Beth R, Alistair G, William C, James U. Anaerobic digestion of harvested aquatic weeds: water hyacinth (Eichchornia Crassipes), cabomba (Cabomba Caroliniana) and salvinia (Salvinia molesta) Ecol Eng 2010; doi:10.1016/j.ecoleng. 2010.06.027.

[25] Aswathy US, Rajeev KS, Devi GL, Rajasree KP, Singhania RR, Pandey A. Bio-ethanol from water hyacinth biomass: An evaluation of enzymatic saccharification strategy. Bioresour Technol 2010; 101: 925-30

[26] Paiva LB, de Oliveira JG, Azevedo RA, Ribeiro DR, da Silva MG, Vitória AP. Ecophysiological responses of water hyacinth exposed to $\mathrm{Cr}^{3+}$ and $\mathrm{Cr}^{6+}$. Environ Exp Bot 2009; 65: 403-9.

[27] Stewart JJP. MOPAC 2002 Version 2.5.3. Tokyo: Fujitsu Limited 2002.

[28] Becke AD. Density-functional thermochemistry. III. The role of exact exchange. J Chem Phys 1993; 98: 5648-52.

[29] Ibrahim M, Kühn O, Scheytt T. Molecular spectroscopic study of water hyacinth dry matter. Open Chem Phys J 2009; 2: 1-6.

[30] Nelson ML, O'Connor RT. Relation on certain infrared bands to cellulose crystallinity and crystal lattice type. Part I: Spectra of lattice types I, II, III and of amorphous cellulose. J Appl Polym Sci, New Orleans 1964; 8:1311-24.

[31] Nelson ML, O'Connor RT. Relation of certain infrared bands to cellulose crystallinity and crystal lattice. Part II: a new infrared ration for estimation of crystallinity in cellulose I and II. J Appl Polym Sci, New Orleans 1964; 8: 1325-41.

[32] Ibrahim M, Al-Fifi Z. Mechanism of pollution control for aquatic plant water hyacinth. Open Spectrose J 2010; 4: 10-14.

[33] Adebajo MO, Frost RL. Acetylation of raw cotton for oil spill cleanup application: an FTIR and C-13 MAS NMR spectroscopic investigation. Spectrochim Acta Part A 2004; 60: 2315-3221.

[34] Wagner RW. Erklärung der dielektrischen Nachwirkungsvorgänge auf Grund Maxwellscher Vorstellungen. Arch Electrotech 1914; 2 : 371-87.

[35] Sillars RW. The properties of dielectrics containing semiconducting particles various shapes. J Inst Elect Eng 1937; 80: 378-94.

[36] Federico M, Galli G, Salvato G. Dielectric relaxations in poly(ethylene oxide) based polymers. Solid State Ionics 1993; 61: 323-6.

[37] Hamaide T, Carre C, Guyot A. Influence of the peo macromonomers on the ionic transport and aging processes in heterogeneous solid polymer electrolytes: a fractal approach. Solid State Ionics 1990; 39: 173-86.

[38] Yager WA, Baker WO. The Relation of Dielectric Properties to Structure of Crystalline Polymers. I. Polyesters. J Am Chem Soc 1942; 64: 2164-71

[39] Hinterstoisser B, Akerholm M, Salmén L. Effect of fiber orientation in dynamic FTIR study on native cellulose. Carbohydr Res 2001; 334: 27-37. 